\title{
Evaluating the Use of Prostate-Specific Antigen as an Instrument for Early Detection of Prostate Cancer beyond Urologists: Results of a Representative Cross-Sectional Questionnaire Study of General Practitioners and Internal Specialists
}

\author{
Christian Gilfrich $^{a}$ Matthias May ${ }^{a}$ Kay-Patrick Braun ${ }^{b}$ Steffen Lebentrau ${ }^{c}$ \\ Mike Lehsnau $^{d}$ Thorsten Ecke ${ }^{e}$ Kurt J.G. Schmailzlc Salah Al-Dumainid \\ Steffen Hallmann ${ }^{\mathrm{e}}$ Ali M. Ahmed ${ }^{\mathrm{a}}$ Julia Maurer ${ }^{\mathrm{a}}$ Thomas Karl ${ }^{\mathrm{a}}$ Vittoria Braun $^{f}$ \\ Axel Haferkamp ${ }^{g}$ Sabine Brookman-May ${ }^{\text {h }}$ Ricarda M. Bauer ${ }^{\text {h }}$ Christian G. Stief ${ }^{\text {h }}$ \\ Bernd Hoschke $^{i}$ Odilo Maurer $^{\mathrm{a}}$ Ingmar Wolff ${ }^{\mathrm{i}}$ \\ a Urologische Klinik, St. Elisabeth-Klinikum, Straubing, bPraxis für Allgemeinmedizin, Cottbus, ' Urologische Klinik, \\ Ruppiner Kliniken, Neuruppin, dUrologische Klinik, Havelland-Kliniken - Klinik Nauen, Nauen, e Urologische Klinik, \\ Helios-Klinik, Bad Saarow, ${ }^{\mathrm{f}}$ Lehrstuhl für Allgemeinmedizin, Charité - Universitätsmedizin Berlin, Berlin, 9Urologische \\ Klinik, Universitätsklinikum der Johann-Wolfgang-Goethe-Universität, Frankfurt am Main, hUrologische \\ Universitätsklinik, LMU, München, and 'Urologische Klinik, Carl-Thiem-Klinikum, Cottbus, Germany
}

\section{Key Words}

Prostate cancer · Early detection · Prostate-specific antigen · General practitioners · Internal specialists · Continuing education

\begin{abstract}
Objectives: The aim of this cross-sectional study was to evaluate the value of prostate-specific antigen (PSA) testing as a tool for early detection of prostate cancer (PCa) applied by general practitioners (GPs) and internal specialists (ISs) as well as to assess criteria leading to the application of PSAbased early PCa detection. Methods: Between May and December 2012, a questionnaire containing 16 items was sent to $600 \mathrm{GPs}$ and ISs in the federal state Brandenburg and in Berlin (Germany). The independent influence of several criteria on the decision of GPs and ISs to apply PSA-based early
\end{abstract}

PCa detection was assessed by multivariate logistic regression analysis (MLRA). Results: 392 evaluable questionnaires were collected (return rate $65 \%$ ). $81 \%$ of the physicians declared that they apply PSA testing for early PCa detection; of these, 58 and $15 \%$ would screen patients until the age of 80 and 90 years, respectively. In case of a pathological PSA level, $77 \%$ would immediately refer the patient to a urologist, while $13 \%$ would re-assess elevated PSA levels after 3-12 months. Based on MLRA, the following criteria were independently associated with a positive attitude towards PSA-based early PCa detection: specialisation (application of early detection more frequent for GPs and hospital-based ISs) (OR 3.12; $\mathrm{p}<$ 0.001 ), physicians who use exclusively GP or IS education (OR

C. Gilfrich and M. May equally contributed to first authorship; O. Maurer and I. Wolff equally contributed to senior authorship.

\section{KARGER}

E-Mail karger@karger.com

www.karger.com/uin (c) 2014 S. Karger AG, Base

0042-1138/14/0932-0160\$39.50/0
Dr. med. Matthias May

Urologische Klinik, St. Elisabeth-Klinikum Straubing

St.-Elisabeth-Strasse 23

DE-94315 Straubing (Germany)

E-Mail matthias.may@klinikum-straubing.de 
3.95; $p=0.002$ ), and physicians who recommend yearly PSA assessment after the age of 50 (OR 6.85; $p<0.001$ ). Conclusions: GPs and ISs frequently apply PSA-based early PCa detection. In doing so, $13 \%$ would initiate specific referral to a urologist in case of pathological PSA values too late. Improvement of this situation could possibly result from specific educational activities for non-urological physicians active in fields of urological core capabilities, which should be guided by joint boards of the national associations of urology and general medicine.

(c) 2014 S. Karger AG, Basel

\section{Introduction}

According to the German interdisciplinary Guideline for Prevention, Diagnostics and Treatment for different stages of prostate cancer ( $\mathrm{PCa}$ ), an early detection of $\mathrm{PCa}$ can be offered to asymptomatic men starting at the age of 40 if their life expectancy is assumed to exceed 10 years [1]. Detailed counselling of patients about potential consequences is mandatory before any method of early detection is performed. After informed consent, the early detection approach should consist of measurement of prostate-specific antigen (PSA) and digital rectal examination of the prostate [1]. An indication for a standardised multicore prostate biopsy is given when one of the following criteria is met: (a) controlled PSA $\geq 4 \mathrm{ng} / \mathrm{ml}$, (b) a digital rectal examination suspicious for PCa or (c) a suspect rise in PSA levels [1].

The impact of a population-based PSA screening for $\mathrm{PCa}$ is still under debate after results of two large randomised controlled studies have been published: the European Randomized Study of Screening for Prostate Cancer (ERSPC) [2] and the Prostate, Lung, Colorectal and Ovarian (PLCO) trial [3]. This has led to inconsistent recommendations in various international guidelines. The U.S. Preventive Services Task Force (USPSTF) argues against PSA-based early PCa detection, while the American Urological Association (AUA), the European Association of Urology (EAU) and the German interdisciplinary S3 guideline recommend that men be thoroughly informed about advantages and disadvantages as well as potential consequences prior to PSA-based early PCa detection $[1,4-6]$.

No data are available on how guideline recommendations concerning PSA-based early PCa detection are applied in daily routine in Germany. Optimally, urologists' diagnostic approaches should be consistent with German interdisciplinary guidelines and the recently published results of the ERSPC and the PLCO trial. On the other hand, it has to be assumed that most men will initially contact their general practitioner (GP) or internal specialist (IS) for early detection of PCa [7-10]. Evidence is lacking about the proportion of population-based $\mathrm{PCa}$ screening initiated by GPs and ISs. In addition, there are no data on which criteria influence early detection strategies applied by GPs and ISs [11, 12].

The aim of this cross-sectional study was to evaluate the value of PSA testing as a tool for early detection of PCa applied by GPs and ISs as well as to assess criteria leading to the application of PSA-based early PCa detection.

\section{Materials and Methods}

\section{Questionnaire}

A questionnaire containing 16 items was designed (table 1) and sent to GPs and ISs. Participants were asked about their specialist medical training, sources used for continuing education concerning PSA testing, and their personal approach to PSA testing for early detection of PCa. It was also assessed how GPs and ISs judge existing evidence for the reduction of PCa-specific mortality by early detection based on PSA testing. In addition, physicians were requested to recommend a treatment option for a 62-year-old, otherwise healthy patient with newly diagnosed low-risk PCa. Finally, GPs and ISs were asked whether they would consider the status of a clinic as a certified PCa centre as opposed to non-certified centres when admitting their PCa patients to hospital for initiation of treatment.

\section{Workflow}

The questionnaire was sent to GPs and ISs in different parts of the federal state of Brandenburg and in Berlin between May and December 2012 - a sufficient period of time after the updated German S3 guideline for early detection, diagnosis and treatment of PCa [1] as well as updated results of the two large international studies on PSA-based screening (ERSPC in March 2012 [2] and PLCO in January 2012 [3]) were published. All office-based GPs and ISs in the following districts in Brandenburg were contacted: Cottbus (54 GPs and 45 ISs), Ostprignitz-Ruppin (47 GPs and 21 ISs), Spree-Neiße (44 GPs and 21 ISs), Oder-Spree (77 GPs and 33 ISs), and Havelland (50 GPs and 28 ISs). In addition, all 133 officebased GPs affiliated with the Charité - University Hospital in Berlin were provided with a questionnaire, resulting in a total number of 533 office-based physicians. As a major part of medical training for GPs is done in internal medicine departments, the questionnaire was also sent to 67 hospital-based ISs in Neuruppin (50) and Nauen (17). Hence, a total of 600 GPs and ISs were asked to fill in the questionnaire.

As the answers were provided in an anonymised fashion, all participants could only be contacted once. All completed questionnaires received until March 1, 2013 were centrally scanned by a high-performance scanner in St. Elisabeth-Klinikum Straubing. The data were then separately tested for plausibility by two authors (A.M.A., O.M.). Data sets that were inaccurately or incompletely assessed were corrected by those two authors whenever unequivocally possible, based on the corresponding questionnaire. The study was approved by the local ethical review board (ERB approved protocol number 12381/13). 
Table 1. Questionnaire comprising 16 items sent to GPs and ISs in the federal state of Brandenburg and in Berlin from May to December 2012

1. Which specialisation do you have, are you board-certified or do you work in a clinic?

$\square \quad$ General practitioner (board-certified, office-based)

$\square \quad$ Internal specialist (board-certified or resident, office-based)

$\square \quad$ General practitioner (non-certified)

$\square \quad$ Combination of specialisations in the office-based sector

$\square \quad$ Internal specialist (board-certified or resident, working in hospitals)

2. When did you complete your specialisation?

$\begin{array}{ll}\square & 0-5 \text { years ago } \\ \square & 6-10 \text { years ago } \\ \square & 11-20 \text { years ago } \\ \square & 21-30 \text { years ago } \\ \square & >30 \text { years ago }\end{array}$

3. Do you use the prostate-specific antigen (PSA) assessment as a screening instrument for detection of PCa?

$\square \quad$ Yes

$\square \quad$ No

4. At which age would you recommend PSA assessment for an asymptomatic man without any familial predisposition?
$\square \quad<40$ years
$\square \quad 41-50$ years
$\square \quad 51-60$ years
$\square \quad 61-70$ years
$\square \quad$ Not at all
$\square \quad$ I cannot answer this question

5. Up to which age would you recommend PSA assessment for an asymptomatic man?
$\square \quad$ Up to 60 years
$\square \quad$ Up to 70 years
$\square \quad$ Up to 80 years
$\square \quad$ Up to 90 years
$\square \quad$ Not at all
$\square \quad$ I cannot answer this question

6. At which cut-off value do you start further actions?

$\begin{array}{ll}\square & >2.5 \mathrm{ng} / \mathrm{ml} \\ \square & >4 \mathrm{ng} / \mathrm{ml} \\ \square & >6 \mathrm{ng} / \mathrm{ml} \\ \square & \text { PSA cut-off adjusted to patient's age } \\ \square & \text { PSA cut-off adjusted to digital rectal examination and free PSA } \\ \square & \text { I cannot answer this question }\end{array}$

7. What is your further management after detecting an increased PSA level according to your own definition in an asymptomatic man?

$\square \quad$ Immediate PSA monitoring after 2-4 weeks

$\square \quad$ Empirical antibiotic therapy, then PSA re-assessment (after 2-4 weeks)

$\square \quad$ PSA assessment after 3-6 months

$\square \quad$ PSA assessment after 7-12 months

$\square \quad$ Urine culture or culture of prostate expressate

$\square \quad$ Referral to a board-certified urologist

$\square \quad$ I cannot answer this question

8. Having decided for PSA monitoring (see question 7) and having received a non-pathological result: What would you do further on?

$\square \quad$ Immediate PSA re-assessment after 2-4 weeks

$\square \quad$ PSA assessment after 3-6 months

$\square \quad$ PSA assessment after 7-12 months

$\square \quad$ Referral to a board-certified urologist

$\square \quad$ I cannot answer this question 
Table 1. (continued)

9. Having decided for PSA monitoring (see question 7) and having received another pathological result: What would you do further on?

$\square \quad$ Immediate PSA re-assessment after 2-4 weeks

$\square \quad$ Empirical antibiotic therapy, then PSA re-assessment

$\square \quad$ PSA assessment after 3-6 months

$\square \quad$ PSA assessment after 7-12 months

$\square \quad$ Urine culture or culture of prostate expressate

$\square \quad$ Referral to a board-certified urologist

$\square \quad$ I cannot answer this question

10. When having decided for an antibiotic therapy after an initially increased PSA level, which substance would you choose?

$\begin{array}{ll}\square & \text { Quinolones } \\ \square & \text { Sulfamethoxazole-trimethoprim } \\ \square & \text { Others } \\ \square & \text { No administration of antibiotics } \\ \square & \text { I cannot answer this question }\end{array}$

11. Do you consider a decrease of PCa mortality by PSA-based screening possible?

$\square \quad$ Yes, as proven by evidence

$\square \quad$ No, as proven by evidence

$\square \quad$ I cannot answer this question

$\square \quad$ A decrease of PCa mortality by PSA-based screening is possible, but more robust data are needed

12. Which of the following treatment strategies would you recommend for a 62 -year-old man without any comorbidities diagnosed with a low-risk PCa (verified by biopsy)?
$\square \quad$ Prostatectomy (open surgery)
$\square \quad$ Prostatectomy (laparoscopic, robot-assisted)
$\square \quad$ Prostatectomy (laparoscopic, extraperitoneal or intraperitoneal)
$\square \quad$ Modern type of percutaneous radiotherapy (e.g. IMRT)
$\square \quad$ Brachytherapy
$\square \quad$ Active surveillance including PSA monitoring and repeated biopsies
$\square \quad$ I cannot answer this question

13. Should an annual PSA assessment beginning at the age of 50 ( 45 for men at risk) become a diagnostic standard approach for an asymptomatic man?
$\square \quad$ Yes
$\square \quad$ No
$\square \quad$ I cannot answer this question
$\square \quad$ At first, yes, but further re-assessment intervals should be adjusted to PSA levels

14. What kind of sources for knowledge acquisition do you use concerning the indication for PSA-based screening?

$\begin{array}{ll}\square & \text { Study of literature/guidelines } \\ \square & \text { GP/IS training (conventions, meetings, round tables) } \\ \square & \text { Urological training (e.g. in certified PCa centres) } \\ \square & \text { Personal contact with urologists } \\ \square & \text { Numerous of given options } \\ \square & \text { None of given options }\end{array}$

15. Do you consider that the aptitude of a clinic as a certified PCa centre goes along with a higher quality of treatment?
$\square \quad$ Yes
$\square \quad$ No, on the contrary
$\square \quad$ I cannot answer this question
$\square \quad$ No, not automatically, but treatment outcome reporting is more transparent

16. Would you recommend your patients being treated in a PCa centre, rather than in a clinic without certification?

$\square \quad$ Yes

$\square \quad$ No, on the contrary

$\square \quad$ Recommendation irrespective of status as PCa centre, status and regional reputation of the clinic in question and of its performance are more important 
Statistical Analysis

The results of nominal scaled items were analysed descriptively. The primary objective and distinguishing feature was the reply to question 1.3: 'Do GPs or ISs use PSA testing as an instrument for early detection of PCa?' (table 1). Bivariate correlations were calculated between item 1.3 and diverse other items (see below) which had been dichotomised before. The Kendall $(\tau)$ correlation coefficient constitutes a dimensionless number with a range between -1 and 1 . Taking into account the orientation of the correlating items, $\tau$ shows a negative $(\tau<0)$ or a positive $(\tau>0)$ correlation, respectively. Moreover, different distributions of dichotomised response options of selected items on the two options of item 1.3 were tested by using Fisher's exact test.

Finally, a multivariate logistic regression analysis (MLRA) was created to test the independent impact of different criteria on the decision of GPs and ISs to use PSA as an instrument for early detection (item 1.3 serving as dependent variable). Different response options of the items, which were included into the MLRA, were combined as far as it made sense with regard to contents and if they showed a reasonable percentage allocated to item 1.3. Thus, it was possible to include independent items regularly dichotomised to the MLRA. The quality of adaption of the MLRA was checked by the likelihood function. In contrast, the coefficient of determination $\mathrm{R}^{2}$ by Nagelkerke shows the proportion of the variance which is explained by logistic regression (ideal: $\mathrm{R}^{2}=1$, consistent with $100 \%)$. In other words, the coefficient of determination acts as a surrogate how fit the MLRA is. When generating the MLRA, a $R^{2} \geq 0.35$ was requested. The impact of different independent variables on the dependent variable is shown by the OR including a $95 \%$ confidence interval. The internal validity of the single variables (indicator items) in the MLRA was analysed by using the bootstrap technique (based on 1,000 random samples). The detected difference of the final coefficient of regression was calculated as slope index (reduction index) and represents the extent of overestimation. In general, the slope index varied from 0 to 1 , while a slope index of 1 excludes an overestimation.

Data analysis was performed using SPSS 20 (IBM Corporation 2011). All $p$ values mentioned in this article are two-sided. The significance level was considered statistically significant for all tests if $\mathrm{p}$ was $\leq 0.05$.

\section{Results}

In total, $65.3 \%(392 / 600)$ of questionnaires were returned. Return rates differed between the three groups of physicians. GPs, office-based ISs and ISs working in hospitals responded in 73\% (282/385), 53\% (78/148) and 48\% (32/67), respectively.

Descriptive statistics are shown in table 2. All items are linked with the corresponding questions of the questionnaire (table 1). PSA testing for early detection of PCa is applied by $81 \%$ of physicians. Among physicians who specified an age limit at which they stop PSA-based early PCa detection, 58.3 and 15\% stop PSA measurements at a patient age of 80 and 90 years, respectively. In total, 331 defined a given cut-off level for PSA testing. Of those, $49.5 \%$ mentioned a cut-off level of $4 \mathrm{ng} / \mathrm{ml}$, which is consistent with the German S3 guideline; 17.2\% preferred age-adjusted cut-off levels.

In case of a pathological PSA level, $76.6 \%$ of the colleagues would decide to immediately refer the patient to a board-certified urologist, while $12.5 \%$ answering this question stated that they would re-assess PSA levels after an interval of 3-12 months themselves. In case of a normal control after an initially pathological PSA level, $39.4 \%$ of the colleagues answering this topic would perform another PSA test after 7-12 months, while $37.4 \%$ would nevertheless refer the patient to a board-certified urologist.

$21.9 \%$ of those physicians taking a definite position on this topic are convinced that reduction of PCa mortality cannot be achieved by PSA-based early PCa detection. In contrast, $35.5 \%$ of the colleagues would favour an explicit guideline recommendation of yearly PSA testing starting at the age of 50 ( 45 for men at risk). $28.3 \%$ of the colleagues stated that their knowledge concerning PSAbased early PCa detection was exclusively generated by continuing GP or IS education. The aptitude of a department as a certified PCa centre is appreciated by almost all colleagues. It represents the main quality criterion for treatment recommendation and referral for $45.7 \%$ of physicians.

Table 3 shows the impact of answers for selected indicator items in dichotomised categories on the willingness of physicians to apply PSA-based early PCa detection. The following groups are most experienced in PSA-based early PCa detection: GPs and ISs working in hospitals, physicians who completed their medical training more than 10 years ago, physicians considering a reduction in PCa mortality by PSA-based early PCa detection possible or proven by evidence, physicians who recommend prostatectomy or percutaneous radiotherapy for low-risk $\mathrm{PCa}$, physicians favouring yearly PSA testing starting at the age of 50, and physicians stating that their knowledge concerning PSA-based early PCa detection was exclusively generated by continuing GP or IS education.

The selected dichotomised indicator items were finally included into a MLRA whose coefficient of determination was required to exceed $35 \%$ (Nagelkerke $\mathrm{R}^{2}=0.39$ ). The following criteria had the highest independent impact on the positive attitude of colleagues outside the urological field towards PSA-based early PCa detection: specialisation, physicians who use exclusively GP or IS education, and physicians who recommend yearly PSA assessment after the age of 50 (table 4). MLRA revealed a high internal validity (slope indices $0.93-0.98$ ). 
Table 2. Experience of participating physicians $(n=392)$ in PSA-based early PCa detection as a function of their specialisation and answers on different indicator questions (items)

\begin{tabular}{|c|c|c|c|}
\hline Items/indicator questions & $\begin{array}{l}\text { All participating } \\
\text { physicians } \\
(\mathrm{n}=392 ; 100 \%)\end{array}$ & $\begin{array}{l}\text { Physicians with PSA-based } \\
\text { early detection experience } \\
(\mathrm{n}=317 ; 80.9 \%)\end{array}$ & $\begin{array}{l}\text { Physicians without } \\
\text { PSA-based early detection } \\
\text { experience }(n=75 ; 19.1 \%)\end{array}$ \\
\hline \multicolumn{4}{|l|}{ Specialisation (item 1) } \\
\hline GP (board-certified) & $255(65.1 \%)$ & $219(69.1 \%)$ & $36(48.0 \%)$ \\
\hline IS (office-based) & $78(19.9 \%)$ & $58(18.3 \%)$ & $20(26.7 \%)$ \\
\hline GP (non-certified) & $27(6.9 \%)$ & $13(4.1 \%)$ & $14(18.7 \%)$ \\
\hline IS (working in hospitals) & $32(8.2 \%)$ & $27(8.5 \%)$ & $5(6.7 \%)$ \\
\hline \multicolumn{4}{|l|}{ Time since specialisation (item 2) } \\
\hline$\leq 5$ years & $50(12.8 \%)$ & $35(11.0 \%)$ & $15(20.0 \%)$ \\
\hline $6-10$ years & $63(16.1 \%)$ & $48(15.1 \%)$ & $15(20.0 \%)$ \\
\hline $11-20$ years & $93(23.7 \%)$ & $81(25.6 \%)$ & $12(16.0 \%)$ \\
\hline $21-30$ years & $120(30.6 \%)$ & $94(29.7 \%)$ & $26(34.7 \%)$ \\
\hline$>30$ years & $66(16.8 \%)$ & $59(18.6 \%)$ & $7(9.3 \%)$ \\
\hline \multicolumn{4}{|c|}{ Age of starting PSA-based early detection (item 4) } \\
\hline$\leq 40$ years & $7(1.8 \%)$ & $7(2.2 \%)$ & 0 \\
\hline $41-50$ years & $139(35.5 \%)$ & $120(37.9 \%)$ & $19(25.3 \%)$ \\
\hline $51-60$ years & $159(40.6 \%)$ & $146(46.1 \%)$ & $13(17.3 \%)$ \\
\hline $61-70$ years & $24(6.1 \%)$ & $21(6.6 \%)$ & $3(4.0 \%)$ \\
\hline No early detection at all or no answer & $63(16.1 \%)$ & $23(7.3 \%)$ & $40(53.3 \%)$ \\
\hline \multicolumn{4}{|c|}{ Age of stopping PSA-based early detection (item 5) } \\
\hline Until the age of 60 & $7(1.8 \%)$ & $4(1.3 \%)$ & $3(4.0 \%)$ \\
\hline Until the age of 70 & $75(19.1 \%)$ & $64(20.2 \%)$ & $11(14.7 \%)$ \\
\hline Until the age of 80 & $179(45.7 \%)$ & $167(52.7 \%)$ & $12(16.0 \%)$ \\
\hline Until the age of 90 & $46(11.7 \%)$ & $43(13.6 \%)$ & $3(4.0 \%)$ \\
\hline No early detection at all or no answer & $85(21.6 \%)$ & $39(12.3 \%)$ & $46(61.3 \%)$ \\
\hline \multicolumn{4}{|l|}{ PSA cut-off (item 6) } \\
\hline$>2.5 \mathrm{ng} / \mathrm{ml}$ & $31(7.9 \%)$ & $25(7.9 \%)$ & $6(8.0 \%)$ \\
\hline$>4 \mathrm{ng} / \mathrm{ml}$ & $164(41.8 \%)$ & $149(47.0 \%)$ & $15(20.0 \%)$ \\
\hline$>6 \mathrm{ng} / \mathrm{ml}$ & $13(3.3 \%)$ & $12(3.8 \%)$ & $1(1.3 \%)$ \\
\hline Age-adjusted PSA cut-off & $57(14.5 \%)$ & $52(16.4 \%)$ & $5(6.7 \%)$ \\
\hline DRE and free PSA adjusted cut-off & $66(16.8 \%)$ & $50(15.8 \%)$ & $16(21.3 \%)$ \\
\hline No answer & $61(15.6 \%)$ & $29(9.1 \%)$ & $32(42.7 \%)$ \\
\hline \multicolumn{4}{|l|}{ Management of pathological PSA (item 7) } \\
\hline PSA monitoring after $2-4$ weeks & $27(6.9 \%)$ & $24(7.6 \%)$ & $3(4.0 \%)$ \\
\hline Antibiotics, then PSA re-assessment & $9(2.3 \%)$ & $9(2.8 \%)$ & 0 \\
\hline PSA monitoring after 3-6 months & $42(10.7 \%)$ & $31(9.8 \%)$ & $11(14.7 \%)$ \\
\hline PSA monitoring after $7-12$ months & $2(0.5 \%)$ & $1(0.3 \%)$ & $1(1.3 \%)$ \\
\hline Urine culture & $2(0.5 \%)$ & $1(0.3 \%)$ & $1(1.3 \%)$ \\
\hline Referral to a board-certified urologist & $269(68.6 \%)$ & $219(69.1 \%)$ & $50(66.7 \%)$ \\
\hline No answer & $41(10.5 \%)$ & $32(10.1 \%)$ & $9(12.0 \%)$ \\
\hline \multicolumn{4}{|l|}{ PSA re-assessment normal (item 8) } \\
\hline PSA re-assessment after $2-4$ weeks & $4(1.0 \%)$ & $3(0.9 \%)$ & $1(1.3 \%)$ \\
\hline PSA re-assessment after 3-6 months & $53(13.5 \%)$ & $46(14.5 \%)$ & $7(9.3 \%)$ \\
\hline PSA re-assessment after $7-12$ months & $97(24.7 \%)$ & $82(25.9 \%)$ & $15(20.0 \%)$ \\
\hline Referral to a board-certified urologist & $92(23.5 \%)$ & $74(23.3 \%)$ & $18(24.0 \%)$ \\
\hline No answer & $146(37.2 \%)$ & $112(35.3 \%)$ & $34(45.3 \%)$ \\
\hline \multicolumn{4}{|l|}{ PSA re-assessment pathological (item 9) } \\
\hline PSA re-assessment after $2-4$ weeks & 0 & 0 & 0 \\
\hline Antibiotics, then PSA re-assessment & $2(0.5 \%)$ & $2(0.6 \%)$ & 0 \\
\hline PSA re-assessment after 3-6 months & $4(1.0 \%)$ & $3(0.9 \%)$ & $1(1.3 \%)$ \\
\hline PSA re-assessment after $7-12$ months & $1(0.3 \%)$ & 0 & $1(1.3 \%)$ \\
\hline Urine culture & $1(0.3 \%)$ & 0 & $1(1.3 \%)$ \\
\hline Referral to a board-certified urologist & $255(65.1 \%)$ & $209(65.9 \%)$ & $46(61.3 \%)$ \\
\hline No answer & $129(32.9 \%)$ & $103(32.5 \%)$ & $26(34.7 \%)$ \\
\hline
\end{tabular}

Use of PSA as an Instrument for Early Detection of PCa
Urol Int 2014;93:160-169 DOI: $10.1159 / 000356367$ 
Table 2. (continued)

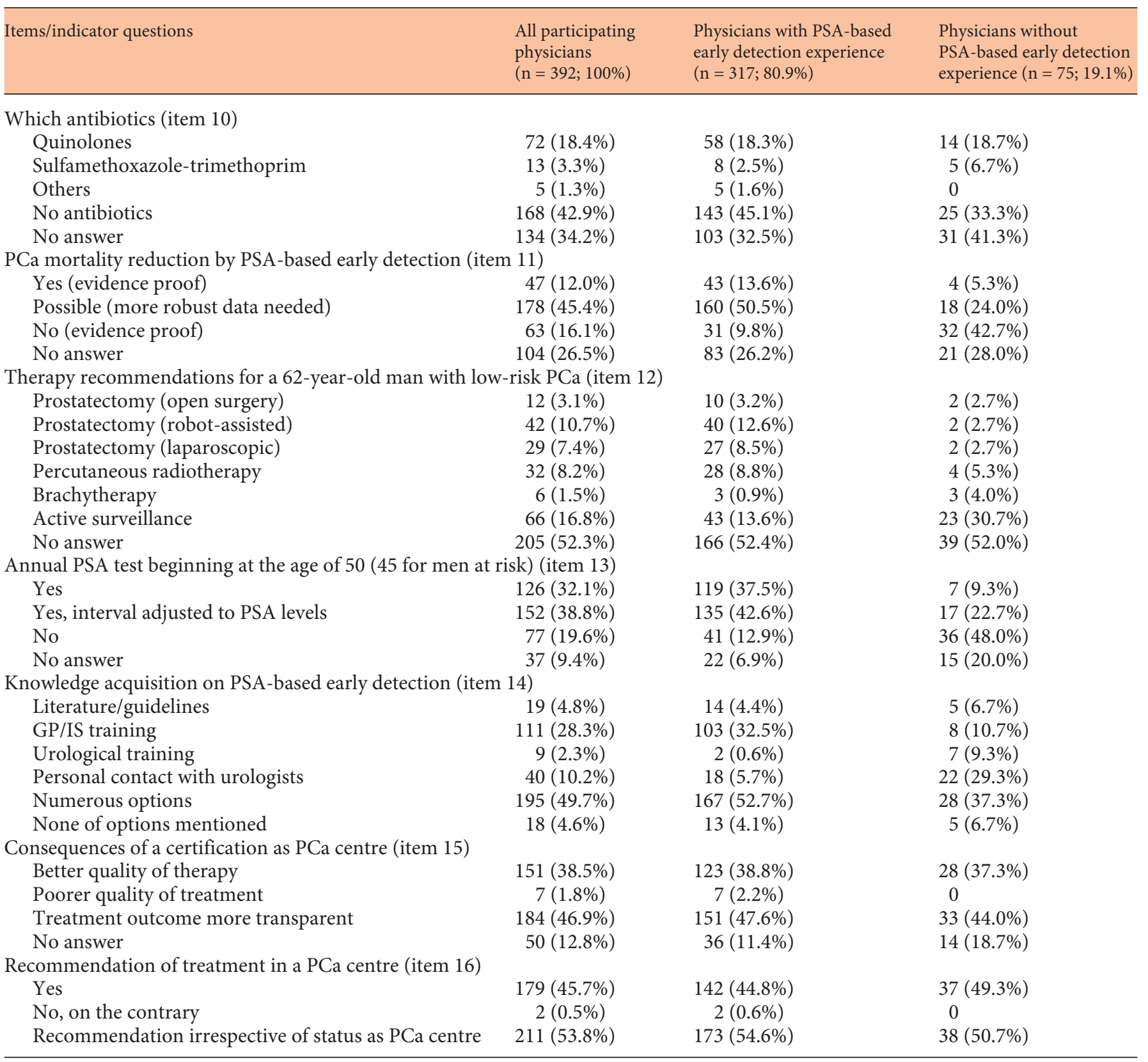

DRE $=$ Digital rectal examination.

\section{Discussion}

PSA-based early PCa detection is still under debate. The effectiveness of population-based PSA screening for PCa could not be finally proven by the two large screening studies, the ERSPC [2] and the PLCO trial [3], despite their different results. In the ERSPC, PCa-specific mortality was found to be reduced by $21 \%$ in the PSA-based early PCa detection group as compared to the control group after a mean follow-up of 11 years [2]. This translates into a reduction of individual cancer-specific risk of mortality of about 3\% without PSA-based early PCa detection to $2.4 \%$ with PSA-based early $\mathrm{PCa}$ detection. In conclusion, the results of this study suggest that 1,055 men have to par- 
Table 3. Distribution of dichotomised response possibilities of selected items on the two options of item 1.3

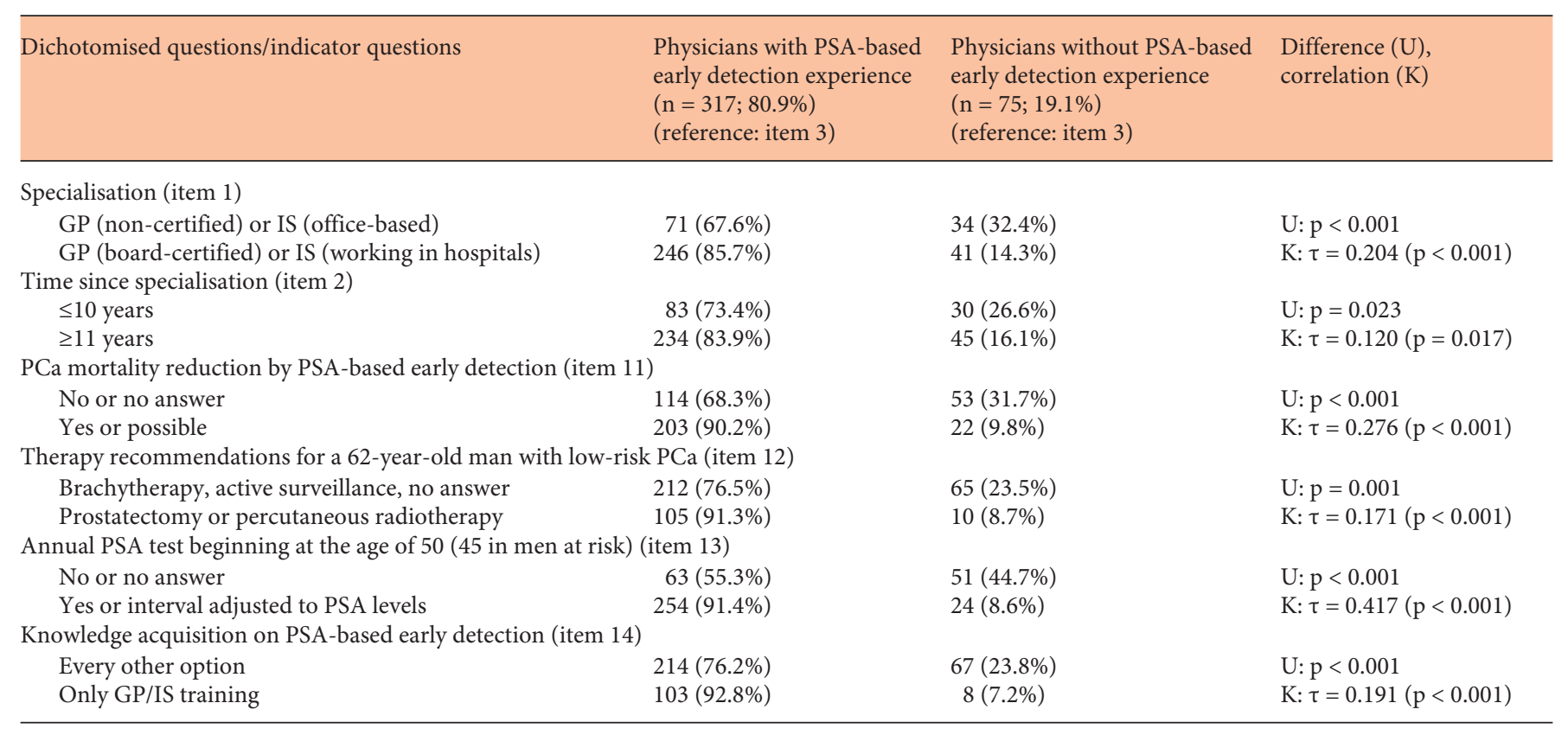

Selection of items and way of dichotomisation was carried out by using reasonable combinations according to the results of table 1 . The extent of difference was tested by using Fisher's exact test, the evaluation of concordance was tested by using the Kendall $(\tau)$ correlation coefficient.

Table 4. MLRA created to test the independent impact of different dichotomised indicator questions on the willingness of GPs and ISs to apply PSA-based early PCa detection

\begin{tabular}{|c|c|c|c|}
\hline Dichotomised items/indicator questions & OR $(95 \% \mathrm{CI})$ & $\mathrm{p}$ & Slope index \\
\hline \multicolumn{4}{|l|}{ Specialisation (item 1) } \\
\hline GP (board-certified) or IS (working in hospitals) (reference: other options) & $3.12(1.66-5.89)$ & $<0.001$ & 0.97 \\
\hline \multicolumn{4}{|l|}{ Time since specialisation (item 2) } \\
\hline$\geq 11$ years (reference: $\leq 10$ years) & $1.86(0.99-3.49)$ & 0.055 & 0.95 \\
\hline \multicolumn{4}{|l|}{ PCa mortality reduction by PSA-based early detection (item 11) } \\
\hline Yes or possible (reference: other options) & $2.03(1.07-3.88)$ & 0.031 & 0.98 \\
\hline \multicolumn{4}{|l|}{ Therapy recommendations for a 62-year-old man with low-risk PCa (item 12) } \\
\hline Prostatectomy or percutaneous radiotherapy (reference: other options) & $3.43(1.51-7.81)$ & 0.003 & 0.93 \\
\hline \multicolumn{4}{|l|}{ Annual PSA test beginning at the age of 50 ( 45 in men at risk) (item 13) } \\
\hline Yes or interval adjusted to PSA levels (reference: other options) & $6.85(3.61-12.98)$ & $<0.001$ & 0.96 \\
\hline \multicolumn{4}{|l|}{ Knowledge acquisition on PSA-based early detection (item 14) } \\
\hline Only GP/IS training (reference: other options) & $3.95(1.67-9.33)$ & 0.002 & 0.94 \\
\hline
\end{tabular}

A coefficient of determination exceeding 35\% was required for inclusion of an indicator question into the MLRA.

$\mathrm{CI}=$ Confidence interval; $\mathrm{OR}=$ odds ratio.

ticipate in PSA-based early PCa detection and 37 men have to undergo therapy in order to save one man's life from PCa within the follow-up period [2]. In another statistical analysis of this study accounting for contamination of the control group by PSA testing of men in this group not indicated by the study protocol, a decrease in PCa mortality of $29 \%$ could be shown for PSA-based early PCa detection [2]. These positive results were even outperformed by the 'Göteborg randomised population-based prostate-cancer screening trial', in which PCa mortality could be reduced by $44 \%$ as compared to the control arm (1 life saved within 12 men who underwent therapy of 293 men screened) 
[13]. Contamination by PSA testing within the control group was one major limitation of the PLCO trial. Therefore, reduction in PCa mortality by PSA-based early PCa detection could not be demonstrated and cannot be expected even after prolongation of the follow-up period [3].

Representative data for the use of PSA-based early PCa detection in Germany are lacking in the urological community as well as in the non-urological field. While urologists are expected to act consistently with the German S3 guideline and findings of the recent literature in order to ensure their expertise [1-6], this cannot be deduced for GPs and ISs by implication. On the other hand, international studies show that PSA-based early PCa detection is widely used by GPs and ISs [7-10, 14-20]. Furthermore, there is no scientific evidence on which consequences are drawn by GPs and ISs based upon given PSA levels in combination with clinical findings. Available study data on this topic illustrate the heterogeneous role of GPs in population-based PSA screening for PCa in various countries [7-10,14-20]. A recently published study by van der Meer et al. [21], exploring the impact of ERSPC results on the implementation of population-based PCa screening by GPs in daily routine, clearly showed the consequences in the region of Rotterdam: (a) after publication of the ERSPC data, fewer PSA tests were performed by GPs in men $\geq 60$ years of age; (b) PSA levels of $4-10 \mathrm{ng} / \mathrm{ml}$ were controlled significantly less frequently; (c) significantly fewer patients with a PSA level $>4 \mathrm{ng} / \mathrm{ml}$ were referred to a board-certified urologist. This possible development mentioned in (b) and (c) is not only questionable in terms of necessary professional prudence, but may also have legal consequences as this can be declared as medical malpractice by committees of valuation experts of the medical associations in Germany [22].

The results of our study constitute the first available data on how GPs and ISs use PSA testing as an instrument for early detection of PCa in Germany. It is shown that PSAbased early PCa detection is performed by four out of five colleagues outside the urological field. Approximately three out of four physicians applying PSA-based early PCa detection would immediately refer patients with a pathological PSA level to a board-certified urologist. In contrast, $13 \%$ would re-assess the PSA level after 3-12 months themselves, which may be considered as arguable referring to the study mentioned above [22]. Almost two thirds of physicians involved in our study (62\%) consider a decrease in PCa mortality by PSA-based early PCa detection possible, but claim more reliable evidence, which might be achieved by further studies. The following criteria were independently associated with a positive attitude of non-urological physicians towards PSA-based early PCa detection: specialisation (application of early detection more frequent for GPs and ISs working in hospitals) (OR 3.12; p $<0.001$ ), physicians who use exclusively GP or IS education (OR $3.95 ; \mathrm{p}=0.002)$, and physicians who recommend yearly PSA assessment after the age of 50 (OR 6.85; p < 0.001).

When interpreting the results of our study, seven limitations have to be considered: (1) Although evaluable questionnaires reached a sufficient number to ensure a robust statistical analysis, the return rate was only $65 \%$. It seems possible that physicians with a thorough knowledge of the topic and highly interested in PSA-based early PCa detection were more motivated to complete the questionnaire. This may have resulted in limited representativeness. (2) GPs and ISs were contacted solely in the federal state of Brandenburg and in Berlin, but this should only minimally influence the translation of the study results for other areas of Germany. However, GPs and ISs might have a different approach to PSA-based early PCa detection in other countries with various health care systems, so that our results may only cautiously be extrapolated under these conditions. (3) Furthermore, it has to be considered that the data presented here resulted from a survey as opposed to exact data acquisition of PSA testing in clinical routine. It remains unclear how many patients are screened by GPs and ISs in reality. (4) It was not differentiated whether GPs and ISs perform real population-based screening or a rather opportunistic PSA-based early PCa detection. (5) No conclusions could be extracted from our study neither concerning the type of counselling about advantages and disadvantages of PSA-based early PCa detection prior to PSA testing nor what kind of information sheets or similar material is used by GPs [23-25]. (6) Moreover, based on our study, we do not know how frequently GPs and ISs combine PSA testing with digital rectal examination as required by the German interdisciplinary S3 guideline for early detection of PCa [1]. (7) Finally, only 39\% of variances that motivated GPs and ISs working in hospitals to apply PSAbased early PCa detection could be illustrated to our MLRA. This implicates that there must be a number of factors on top of those considered in our model that influence decision-making by GPs and ISs concerning PSAbased early PCa detection. Despite these limitations, we believe that the results of this first German study analysing the application of PSA testing as a tool for early detection of PCa may shed some light on which knowledge and which motivation guide GPs and ISs in using it.

In summary, about four out of five colleagues in the field of general and internal medicine perform early detection of PCa by assessment of PSA levels. More than 
three out of four physicians would refer patients with pathological PSA levels immediately to a board-certified urologist for further diagnostics. Approximately $13 \%$ of colleagues outside the urological field may wait too long before re-evaluating increased PSA levels. The following criteria were independently associated with a positive attitude of non-urological physicians towards PSA-based early PCa detection: specialisation (application of early detection more frequent for GPs and ISs working in hospitals), physicians who exclusively use GP or IS education, and physicians who recommend yearly PSA assessment after the age of 50. Specific educational activities for non-urological physicians active in fields of urological core capabilities should be guided by joint boards of the national associations of urology and general medicine.

\section{Disclosure Statement}

None of the authors has to declare any conflict of interest. All authors read and approved the manuscript. Sabine BrookmanMay is employed as a medical scientist by Janssen-Cilag, but this fact does not interact with this study. The corresponding author (Matthias May) had complete access to all source data analysed in this study and is fully responsible for data analysis.

\section{References}

1 Leitlinienprogramm Onkologie. Interdisziplinäre Leitlinie der Qualität S3 zur Früherkennung, Diagnose und Therapie der verschiedenen Stadien des Prostatakarzinoms. Version 2.0, 1. Aktualisierung 09.2011.

-2 Schröder FH, Hugosson J, Roobol MJ, Tammela TL, Ciatto S, Nelen V, Kwiatkowski M, Lujan M, Lilja H, Zappa M, Denis LJ, Recker F, Páez A, Määttänen L, Bangma CH, Aus G, Carlsson S, Villers A, Rebillard X, van der Kwast T, Kujala PM, Blijenberg BG, Stenman UH, Huber A, Taari K, Hakama M, Moss SM, de Koning HJ, Auvinen A; ERSPC Investigators: Prostate-cancer mortality at 11 years of follow-up. N Engl J Med 2012;366: 981-990.

3 Andriole GL, Crawford ED, Grubb RL 3rd, Buys SS, Chia D, Church TR, Fouad MN, Isaacs C, Kvale PA, Reding DJ, Weissfeld JL, Yokochi LA, O’Brien B, Ragard LR, Clapp JD, Rathmell JM, Riley TL, Hsing AW, Izmirlian G, Pinsky PF, Kramer BS, Miller AB, Gohagan JK, Prorok PC; PLCO Project Team: Prostate cancer screening in the randomized Prostate, Lung, Colorectal, and Ovarian Cancer Screening Trial: mortality results after 13 years of follow-up. J Natl Cancer Inst 2012;104:125-132.

4 Screening for Prostate Cancer, Topic Page. U.S. Preventive Services Task Force. http:// www.uspreventiveservicestaskforce.org/ prostatecancerscreening.htm.

5 http://www.auanet.org/common/pdf/ education/clinical-guidance/Prostate-CancerDetection.pdf.

6 Heidenreich A, Bellmunt J, Bolla M, Joniau S, Mason M, Matveev V, Mottet N, Schmid $\mathrm{HP}$, van der Kwast T, Wiegel T, Zattoni F; European Association of Urology: EAU guidelines on prostate cancer. Part 1: screening, diagnosis, and treatment of clinically localised disease. Eur Urol 2011;59:61-71.

-7 Williams N, Hughes LJ, Turner EL, Donovan JL, Hamdy FC, Neal DE, Martin RM, Metcalfe C: Prostate-specific antigen testing rates remain low in UK general practice: a cross-sec- tional study in six English cities. BJU Int 2011; 17 Jønler M, Eddy B, Poulsen J: Prostate-specific 108:1402-1408.

-8 Tasian GE, Cooperberg MR, Potter MB, Cowan JE, Greene KL, Carroll PR, Chan JM: PSA screening: determinants of primary-care physician practice patterns. Prostate Cancer Prostatic Dis 2012;15:189-194.

-9 Volk RJ, Linder SK, Kallen MA, Galliher JM, Spano MS, Mullen PD, Spann SJ: Primary care physicians' use of an informed decisionmaking process for prostate cancer screening. Ann Fam Med 2013;11:67-74.

10 Hayat Roshanai A, Nordin K, Berglund G: Factors influencing primary care physicians' decision to order prostate-specific antigen (PSA) test for men without prostate cancer. Acta Oncol 2013;52:1602-1608.

11 Braun KP, May M, Grassmel Y, Führer S, Hoschke B, Braun V: The general practitioner's part in the initiation of diagnostic procedures in prostate cancer. Aktuelle Urol 2008;39: 141-146.

12 Braun KP, Brookman-Amissah S, May M, Grassmel Y, Hoschke B, Braun V: The assessment of pathological PSA values by the general practitioner - observation or intervention? Aktuelle Urol 2009;40:171-174.

13 Hugosson J, Carlsson S, Aus G, Bergdahl S, Khatami A, Lodding P, Pihl CG, Stranne J, Holmberg E, Lilja H: Mortality results from the Göteborg randomised population-based prostate-cancer screening trial. Lancet Oncol 2010;11:725-732.

14 Durham J, Low M, McLeod D: Screening for prostate cancer: a survey of New Zealand general practitioners. N Z Med J 2003;116:U476.

15 Little B, Ho KJ, Gormley G, Young M: PSA testing in general practice. Prostate Cancer Prostatic Dis 2003;6:154-158.

16 Melia J, Moss S, Johns L; Contributors in the participating laboratories: Rates of prostatespecific antigen testing in general practice in England and Wales in asymptomatic and symptomatic patients: a cross-sectional study. BJU Int 2004;94:51-56. antigen testing in general practice: a survey among 325 general practitioners in Denmark. Scand J Urol Nephrol 2005;39:214-218.

18 Brett J, Watson E, Hewitson P, Bukach C, Edwards A, Elwyn G, Austoker J: PSA testing for prostate cancer: an online survey of the views and reported practice of General Practitioners in the UK. BMC Fam Pract 2005;6:24.

19 Rochester MA, Donaldson PJ, McLoughlin J: Perception of abnormal serum prostate-specific antigen (PSA) test results amongst family practitioners. Ann R Coll Surg Engl 2008; 90:398-402.

20 D’Ambrosio GG, Campo S, Cancian M, Pecchioli S, Mazzaglia G: Opportunistic prostatespecific antigen screening in Italy: 6 years of monitoring from the Italian general practice database. Eur J Cancer Prev 2010;19:413-416.

21 van der Meer S, Kollen BJ, Hirdes WH, Steffens MG, Hoekstra-Weebers JE, Nijman RM, Blanker MH: Impact of the European Randomized Study of Screening for Prostate Cancer (ERSPC) on prostate-specific antigen (PSA) testing by Dutch general practitioners. BJU Int 2013;112:26-31.

22 Lent V, Baumbusch F, Weber B: Criteria for errors in prostate-specific antigen diagnostics. Urologe A 2012;51:1558-1561.

23 Nicolaiew N, Ploussard G, Chun FKH, Xylinas E, Allory Y, Salomon L, de la Taille A: Prediction of the risk of harboring prostate cancer by a prebiopsy nomogram based on extended biopsy protocol. Urol Int 2013;90:306-311.

24 Okihara K, Mikami K, Kamoi K, Kitamura K, Kawauchi A, Miki T: Assessment of screenees' knowledge on prostate cancer: results of a questionnaire using the fact sheet. Urol Int 2013;91:49-54.

25 Torky M, Mosharafa A, Emran A, Kamal A, Abdelhamid M: Antimicrobial therapy for asymptomatic patients with elevated prostatespecific antigen: can the change in prostatespecific antigen reliably guide prostate biopsy decisions? Urol Int 2011;87:416-419. 